\title{
ENSOÑACIÓN DE LA LÍNEA Y SU SOMBRA
}

\author{
«Estas cosas que viven alejándose \\ quieren que las transformemos del todo \\ en el corazón sensible, en nosotros, infinitamente».
}

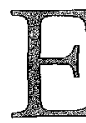

STOS VERSOS DE R. MARIA RILKE me parecieron un iluminado principio como comentario a la edición de una serie de propuestas para concursos de arquitectura realizados en la década de los sesenta; eran sin dudar una generosa valoración crítica, y esta invocación poética, como pretérito de aquel tiempo y así lo intento describir: mi tiempo, tan flexible como precario, se debatía en aquella década subvencionado por nóminas de mil recursos, controlados por aquellas burocracias de gestores mínimos para acoger aquella modernidad en arquitectura y otros menesteres de la vida con agresiva templanza; modernidad raptada para inmolarla en preces y beneficios en la incipiente teología del mercado.

La práctica del proyecto de la arquitectura, en mi caso, respondía a difusas ensoñaciones de la línea y sus sombras; edificar se presentaba como bucear en el alma y la dimensión poética de la materia casi como un axioma: edificar es ordenar el espacio de la arquitectura desde la geometría y las aritméticas que controlan la materia, y el resto es sombras. Pero ¿̧a qué respondía el pensamiento arquitectónico de la época en la trama consolidada del espacio racional moderno, en la taxonomía históricar: Movimiento Moderno en Arquitectura (MMA).

El pensamiento arquitectónico durante este período (I960I $\left.97^{\circ}\right)$ ha transcurrido, como ya he señalado en otras referencias 
críticas, con una decidida actitud de encuentro, primero intentando acercarse a una definición y cuantificación de los problemas que solicita y requiere el espacio de la arquitectura dentro de los saberes de las ciencias exactas y sociales; más tarde intentando recuperar el «aura eclipsada» por medio de la gestión simbólica ante la ambigüedad y variedad de las metodologías de diseño, cuyo cometido se proponía cómo resolver la presencia del hombre dentro del espacio contemporáneo como escenario y lugar, más allá de los cometidos funcionales de la década de los veinte.

Mis primeros proyectos y modestos enunciados críticos se manifestaban registrados en el prólogo de la exposición Obras y pensamientos gráficos, de la Sala de Cultura, Caja de Ahorros de Pamplona, febrero de 1973.

«El respeto a la razón; el reconocimiento palpable de los sentidos como fuente de conocimiento; la vuelta a la proporción, como proceso integrador de los elementos que intervienen en la construcción del espacio; la disonancia formal como invariante característica para la libertad del proyecto. El diseño concebido como creación, e innovación. La valoración del hecho histórico como memoria del espacio que permite interpretar los fenómenos de resistencia, adaptación y supervivencia de la forma arquitectónica.

"Las propuestas orgánicas de sus primeros trabajos, han desarrollado posteriormente aquellas intuiciones escolares que podían observarse en trabajos iniciales. La forma arquitectónica se genera en el medio natural, pero no adaptándose a través de diseños de analogías formales, sino transformándolo radicalmente: su trabajo se articula más por principios que formalizando conclusiones».

Algunos arquitectos y tendencias que por entonces se postulaban como doctrina, en lugar de ordenar con cierto rigor las finalidades del proyecto arquitectónico, se trasladaban a la «colina de los vientos», en precisa metáfora de Léon Krier, lugar donde poder iniciar y superar la crisis estética que encerraban, al parecer, las formas radicales de la ortodoxia funcionalista; en fin, la permanente tensión entre forma-función y contenido espacial que demanda el proyecto de la arquitectura.

Frente a las metodologías científicas no artísticas, se levantaron las insinuaciones críticas de quienes entendían que 
el proyecto arquitectónico para la ciudad surgía de un equívoco interdisciplinar, junto a la debilidad asumida por el arquitecto al dejarse invadir su territorio proyectual por otros saberes no específicos del arte de construir. Recuperar la artisticidad arquitectónica ha sido durante este prolongado período una batalla bien secundada por los ejercicios formales de las diferentes corrientes críticas y «tendencias» como lo han sido las aproximaciones neo-clásicas o ciertas regresiones posmodernistas, requeridas, tal vez, por la incapacidad de poder incidir y modificar la realidad ambiental desde el discurso objetivo de la forma; en tal situación los saberes arquitectónicos se repliegan en círculos minoritarios que intentan recuperar en escuelas y academias un público de dóciles escolares y singulares usufructuarios. Las muestras de adhesión fueron más que evidentes con estas manifestaciones bien recibidas por parte de los pedagogos de la arquitectura, justificadas por la dosis de idealismo que sus símbolos formales comportaban o por el grado de seducción que el simulacro siempre les confiere.

El nuevo contenido «utópico» de estos proyectos que refiere el período valorado por el profesor González-Capitel, estaría enfocado a indagar, de nuevo, el interior de la aventura española de la modernidad en la arquitectura, pero en sentido reformador respecto al retraso que había significado la guerra civil de I936, y será la "condición posmoderna» la referencia ideológica con la que tendrá que contar la futura especulación formal en los gestos del proyecto y el desarrollo económicosocial de los intereses de la economía de mercado.

Por aquellos años, septiembre de 1973, publicaba un pequeño homenaje de recuerdo de los que fueron para muchos de nosotros los grandes maestros de la nueva arquitectura. La obra de los maestros constructores se oculta ya en la historia lejana, en una época entendida como necesaria. Buscar el presente es el sentido del trabajo para los arquitectos dispuestos a romper con la arquitectura burguesa. Sus propuestas llevaban implícita la necesidad de dosificar observaciones diversas, actitudes éticas, códigos de una moral más generosa, formas implicadas en concebir una espacialidad para la cual no existe un tiempo de reflexión, aunque sobren medios. Proyectos, los aquí referidos, empeñados en valorar el espacio frente a los cometidos de una época, que aún mantiene en alto grado el recelo 
arquitectónico o adherencias pequeño-burguesas a la hora de interpretar la arquitectura.

Todo ello comporta unos resultados de arquitectura confusa, cargada de disciplinas paralelas y de abandonos (mercantilización del racionalismo, inoperancia de las escuelas, predominio de la edificación inmobiliaria como relato arquitectónico), pero también de búsqueda de nuevas cuestiones, formulación de teorías, solicitación de nuevas alternativas ${ }^{6}$.

La arquitectura por la que discurren las corrientes ideológicas italianas asume la interpretación de la modernidad evidentemente ecléctica: despliegue teórico de aproximaciones a la heterodoxia marxista, junto con el intento de integrar las recuperaciones formales de la romanidad fascista-racionalista de los años treinta, sin olvidar los efectos ilusorios con los que irrumpía el funcionalismo kitsch en los Estados Unidos; elementos que servirían de aglutinadores para incorporar tanto en Europa como en Norteamérica a un grupo destacado de «ilustradores gráficos», responsables arquitectos y diseñadores de objetos que van a protagonizar, con tal operación, el poder identificar con un sentido de totalidad, como en los iniciales años del siglo XX el «proyecto moderno de la arquitectura de la ciudad" para la nueva sociedad surgida de la segunda posguerra europea.

Las consignas formuladas de la época no fueron muy precisas, la confusión de conceptos tan diferenciados como posindustrialismo y posmodernismo permitirá a la arquitectura americana situarse en el centro de la polémica y asumir el papel de vanguardia, como protagonista en ciertos aspectos de la recuperación de la modernidad arquitectónica, papel que salvo los grandes colosos del espacio arquitectónico americano apenas habían podido manifestar sus arquitectos.

A estas consideraciones se uniría la incapacidad de las últimas Tendencias, como ya se ha señalado, para dar respuesta a la compleja espacialidad contemporánea, intentando obviarla por una salida de espacialidad de tonos románticos, donde la reaparición de una subjetividad enaltecida por los media de la información plástica pretende recuperar la autoridad moral de la forma, pese

- Cinco cuestiones de arquitectura, Madrid: Taller de Ediciones Josefina Betancor, I974. 
a tan manifiesto mensaje, la energía de la forma se transformaba en el poder del signo, y en hacer patente el protagonismo de la arquitectura mediante una estandarización del espacio, como de manera evidente se ha verificado en los finales del siglo XX. Los signos neorrománticos en que venía envuel to el nuevo marketing del relato arquitectónico, anuncia la pérdida de protagonismo y alguno de los valores políticos, sociohistóricos y científicos que caracterizó en parte la década de los sesenta, donde se inscriben las propuestas de estos proyectos.

Entre los postulados formales que arropan las tendencias arquitectónicas o las visiones planificatorias de la época, no deja de ser elocuente la fractura de la belleza en el diseño del proyecto. La moderna arquitectura vinculada siempre con sus postulados con el arte y con la vida hace patente este vacío acumulando alrededor del proyecto: múltiples ambigüedades formales e ingenuos espacios de mediocridad junto a un alto grado de libertad expresiva; cubrir el vacío de ambas situaciones, vida y belleza, ha sido, a través de la historia, la aventura ensoñada por la arquitectura, no solo a través de proyectos imaginarios, sino intentando siempre equilibrar las relaciones entre artificio, técnica y naturaleza.

La pérdida de la dimensión estética lleva consigo la adulteración del medio donde el hombre desarrolla su hábitat, de ahí la necesidad en el control del espacio físico por otros sistemas de organización económica, que las fórmulas de colonización mercantil que, entonces y en la actualidad son los determinantes del simulacro del discurso arquitectónico y la banalización intelectual de su arquitectura en el contexto de la planificación del desarrollo de nuestras metrópolis y ciudades.

Los espacios de la arquitectura donde se asientan las sociedades divididas en estas décadas vienen a ser como reservas marginales, donde la moral ha sido suplantada por los mercados de la equivalencia y el tráfico indiscriminado de la belleza simulada pretende suplir las demandas simbólicas del hombre cosificado; se acepta el design pero pierden valor los mensajes plásticos del arte de vanguardia.

Estas notas escritas desde la mirada del testigo en el oficio de arquitecto en 1973 esbozaban un interrogante antropológico no muy preciso por aquellos años: ¿las conquistas de una tecnología avanzada son suficientes para formalizar nuestro entorno vital y construir los lugares de la ciudad? 
Señalaban mi admiración y aprendizaje por caudal tan prodigioso en la formalización del proyecto de la arquitectura aceptando que el Movimiento Moderno, pese a tanta reticencia condenatoria, significó un salto importante en el descubrimiento de significativos resortes culturales, los cuales promueven los procesos del edificar lo arquitectónico. Su empeño pretendió enunciar la espacialidad como un factor de la realidad equidistante entre el proyecto del arquitecto y las necesidades del usuario. La ruptura ideológica que llevaba implícito este movimiento, junto a la dificultad de hacerla explicita, obligó a trabajar y refugiarse en las fortalezas del magisterio individual a muchos de sus pioneros.

No obstante, y tal vez debido a esta circunstancia, los trabajos realizados por los maestros constructores se manifestaron como generosos ejercicios de expresión y compromiso, entre los cuales el espacio arquitectónico formalizó significativos hallazgos.

La muerte de los maestros, solidaria a la de los epígonos, señaló más tarde diferencias esenciales...; no era ya la gloria, sino la liberación, el significado de la Arquitectura. Tanteos más o menos conscientes, numerosos ensayos, nuevos mitos y una secuencia de proyectos realizados. El expresionismo arquitectónico anunciaba su presencia saltando las correctas normas de los epigonos, desde Estados Unidos al Japón, y su lenguaje aparecía como un discurso formal, en el cual la estructura mecánica y la textura del material configuraban sus aspectos significativos, dominio, en definitiva, de la materia técnica, pero cla naturaleza del hombre se puede captar solo por el dominio técnico?

Añadiría ahora desde el sosiego del superviviente que el pensamiento arquitectónico, desde los finales del siglo precedente y en la década ya cumplida del siglo XXI, se encuentra con otros tiempos y demandas espaciales: la preferencia de la forma arquitectónica sobre la lógica funcional de sus ambientes, la hiperformalización abstracta y compositiva frente a la experiencia del modelo construido, la atracción por la apariencia, ingravidez y trasparencia de la envolvente del edificio, junto, como ya se ha señalado, a la veneración indiscriminada por lo móvil y aleatorio que alejan y, a veces, nublan el rigor del método, la deconstrucción de la estructura resistente, el equilibrio del artefacto sobre el medio y la función de la materia en la evolución 
del proceso edificatorio..., esquemas al parecer ya periclitados de la ortodoxia del Movimiento Moderno en Arquitectura (MMA), territorio abonado donde crecían como «flores silvestres» estos seis proyectos que comento en estas fragmentarias valoraciones críticas.

No sé si el grado de incertidumbre permite contemplar el proyecto de la arquitectura para la metrópoli del segundo milenio, aún tangente a los giros y aceleraciones de un vocablo inestable e indefinido de la posmodernidad, herencia poco tranquilizadora ante el luminoso poliedro, aún por esclarecer de la modemidad, en ese itinerario de brumas que recorre el proyecto racional de la arquitectura al encuentro con el espacio y el lugar sobre un mundo en perpetua y acelerada rotación.

Contemplando hoy, cuarenta y cinco años después, aquellas ensoñaciones de la línea y sus sombras, las colosales arquitecturas que colonizan el espacio público y privado de nuestras metrópolis y ciudades, tal vez podamos entender mejor aquellos axiomas que manifiestan, cómo el saber científico-técnico está más incorporado en el capital y en sus familias de máquinas, de manera que el proyecto de la arquitectura viene predeterminado por esa figura abstracta y difuminada del capital y que confirman la precisión de aquel viejo epigrama que se atribuye a Alejandro: «Para mí, la Tierra; tú, Zeus, conténtate con el Olimpo». 